\title{
Divergent Function of Programmed Death-Ligand 1 in Donor Tissue versus Recipient Immune System in a Murine Model of Bronchiolitis Obliterans
}

\author{
Katharina Schütte-Nütgen, ${ }^{* \dagger}$ Olaf Boenisch, ${ }^{\ddagger \S}$ Hakima Harrach, ${ }^{*}$ Alicia Casey, ${ }^{*}$ Indira Guleria, ${ }^{\ddagger}$ Nader Najafian, \\ Mohamed H. Sayegh," Craig J. Gerard, ${ }^{*}$ and Meera Subramaniam*
}

\begin{abstract}
From the Pulmonary Division, * Boston Children's Hospital, Harvard Medical School, Boston, Massachusetts; the Department of Internal Medicine D, ${ }^{\dagger}$ University Hospital Münster, Münster, Germany; the Transplantation Research Center, ${ }^{\ddagger}$ Brigham and Women's Hospital and Boston Children's Hospital, Harvard Medical School, Boston, Massachusetts; the Department of Nephrology and Hypertension, ${ }^{\S}$ Hannover Medical School, Hannover, Germany; and the Medical Faculty, American University of Beirut, Beirut, Lebanon
\end{abstract}

Accepted for publication

February 6, 2017.

Address correspondence to Meera Subramaniam, M.D. Pulmonary Division, Boston Children's Hospital, Harvard Medical School, 300 Longwood Ave, Boston, MA 02115. E-mail: meera.subramaniam@ childrens.harvard.edu.

\begin{abstract}
Costimulatory molecules, such as the programmed death ligand (PD-L1), might exert differential effects on T-cell function, depending on the clinical setting and/or immunological environment. Given the impact of $T$ cells on bronchiolitis obliterans (BO) in lung transplantation, we used an established tracheal transplant model inducing B0-like lesions to investigate the impact of PD-L1 on alloimmune responses and histopathological outcome in B0. In contrast to other transplant models in which PD-L1 generally shows protective functions, we demonstrated that PD-L1 has divergent effects depending on its location in donor versus recipient tissue. Although PD-L1 deficiency in donor tissue worsened histopathological outcome, and increased systemic inflammatory response, recipient PD-L1 deficiency induced opposite effects. Mechanistic studies revealed PD-L1-deficient recipients were hyporesponsive toward alloantigen, despite increased numbers of $\mathrm{CD} 8^{+}$effector T cells. The function of PD-L1 on T cells after unspecific stimulation was dependent on both cell type and strength of stimulation. This novel function of recipient PD-L1 may result from the high degree of T-cell activation within the highly immunogenic milieu of the transplanted tissue. In this model, both decreased T-cell alloimmune responses and the reduction of $\mathrm{BO}$ in $\mathrm{PD}$-L1-deficient recipients suggest a potential therapeutic role of selectively blocking PD-L1 in the recipient. Further investigation is warranted to determine the impact of this finding embedded in the complex pathophysiological context of B0. (Am J Pathol 2017, 187: 1368-1379; http://dx.doi.org/10.1016/j.ajpath.2017.02.007)
\end{abstract}

T-cell-mediated alloimmune responses limit allograft and patient survival after solid organ transplantation. ${ }^{1,2}$ Manipulating the complex process of T-cell activation in the setting of solid organ transplantation is a promising approach to limit T-cell-mediated alloimmune reactions and subsequent allograft tissue damage. Optimal activation of naïve $\mathrm{T}$ cells to acquire an effector phenotype requires two types of signals. The first signal is provided by the interaction of the antigen-specific T-cell receptor with the antigen presented in conjunction with the major histocompatibility complex on antigen-presenting cells (signal one), but this signal alone is not sufficient to elucidate T-cell activation by itself. A second signal, mediated by costimulatory molecules, is needed to achieve optimal T-cell activation. As these costimulatory pathways can be either activating (positive) or regulating (negative) in nature, the net effect of costimulatory signals determines the outcome of the immune response. ${ }^{3}$ An important costimulatory pathway is the programmed death-1 (PD-1)/programmed death-ligand 1 (PD-L1) system. PD-L1

\footnotetext{
Supported by NIH grant KO8 HL084242-01 and Boston Children's Hospital institutional support (M.S.).

K.S.-N., O.B., and H.H. contributed equally to this work.

Disclosures: None declared.

Current address of O.B., Department of Intensive Care Medicine, University Hospital Hamburg-Eppendorf, Hamburg, Germany.
} 
(B7-H1; CD274) and its receptor PD-1 (CD279) belong to the CD28 family of coreceptors that are involved in T-cell activation and tolerance signals. ${ }^{4-6}$ In many studies, the interaction of PD-1 with PD-L1 has been shown to decrease $\mathrm{T}$-cell proliferation and survival of $\mathrm{T}$ cells and is generally thought to exert inhibitory functions in experimental models of autoimmune diseases, chronic viral infections, response to tumors, and tissue transplantation. ${ }^{3,7-10}$ In contrast, some authors suggest that PD-L1 enhances T-cell activation and proliferation. $^{11}$

Despite the important role of PD-L1 in T-cell biology and increasing knowledge of the function of PD-L1 in solid organ transplantation, its role in lung transplantation is unknown. Lung transplantation is the only definitive treatment available for patients with end-stage lung diseases, such as chronic obstructive pulmonary disease, idiopathic pulmonary fibrosis, cystic fibrosis, $\alpha 1$-antitrypsin disease, and primary pulmonary hypertension. ${ }^{12,13}$ Major improvements in surgical techniques, novel immunosuppressive agents, and control of infections have improved 1-year survival after lung transplantation to $70 \%$ to $80 \%$, but long-term survival is still limited because of persistent immune injury resulting in chronic rejection processes that manifest as bronchiolitis obliterans (BO). ${ }^{13,14} \mathrm{BO}$ is clinically characterized by the progressive loss of lung function due to airflow obstruction, characteristic of bronchiolitis obliterans syndrome and eventually resulting in respiratory failure and death. BO-related mortality remains alarmingly high, with only $40 \%$ to $50 \%$ patient survival 5 years after the onset of $\mathrm{BO}$. The lung has the highest rejection rates among all solid organ transplants, probably as the result of epithelial immunological vulnerability and injury because of its constant exposure to airborne antigens, pathogens, and pollutants. Consequently, even more than three decades after the first lung transplant, BO remains a daunting challenge, with no effective therapies. ${ }^{12,14,15}$ Etiology and pathophysiology of $\mathrm{BO}$ are poorly understood; it comprises loss of airway epithelium, peribronchial inflammation, immune injury, and subsequent airway fibrosis, leading to obliterative airway disease. ${ }^{12}$ Repair mechanisms during BO are insufficient because of the complex nature of immune injury. During the past years, humoral immunity, including both human leukocyte antigen and non-human leukocyte antigen antibodies, as well as autoimmunity and complement activation have been identified as important mechanisms that contribute to the outcome after lung transplantation, ${ }^{16}$ and the fact that $\mathrm{BO}$ is resistant toward currently used immunosuppressive strategies suggests a complexity in the immune pathogenesis that requires further elucidation. ${ }^{13}$ Effector $\mathrm{T}$ cells, however, appear to be important mediators of immune injury leading to $\mathrm{BO}$, as adoptive transfer of effector $\mathrm{T}$ cells into mice lacking $\mathrm{T}, \mathrm{B}$, and natural killer cells causes BO. ${ }^{17}$ It has also been shown that $\mathrm{CD} 8^{+} \mathrm{T}$ cells activated by major histocompatibility complex class I molecules can cause obliterative airway disease. ${ }^{18}$ It is therefore essential to identify the mechanisms by which activated effector $\mathrm{T}$ cells are recruited and contribute to the pathogenesis of $\mathrm{BO}$.

In this study, we investigated the function of PD-L1 in a heterotopic tracheal transplant model. Although this model does not reflect all pathophysiological components involved in $\mathrm{BO}$, it does provide the opportunity to analyze histopathological features of $\mathrm{BO}$, as like human $\mathrm{BO}$ it is alloimmune mediated and presents with luminal obliteration and loss of airway epithelium. This allows us to investigate the systemic alloimmune response in a highly immunogenic environment, particularly T-cell-mediated effects, which play a major role in this model and influence the histopathological outcome.

The presented data suggest a divergent role of PD-L1 in the donor tissue versus the immune system of the graft recipient, which has impact for the preservation of the respiratory epithelium and the alloimmune responses after transplantation, particularly for the development of effector $\mathrm{T}$ cells.

\section{Materials and Methods}

\section{Mice}

Wild-type (WT) C57BL/6 (H-2 ${ }^{\mathrm{b}}$, B6) and BALB/c (H-2 $\left.{ }^{\mathrm{d}}\right)$ mice were purchased from Taconic (Germantown, NY). PD-L1- and PD-1-deficient (PD-L1 ${ }^{-/}$, PD- $^{-/-}$) mice on the B6 background were obtained from I.G. and M.H.S. and maintained as a breeding colony in our animal facility. All mice were used at 8 to 12 weeks of age and all animal protocols were approved by the Boston Children's Hospital Animal Care and Use Committe.

\section{Heterotopic Airway Transplant Model}

All studies were performed according to institutional guidelines for animal use and care. We used an established model of obliterative airway disease involving heterotopic tracheal transplant with major histocompatibility complex-mismatched donor and recipient combinations of $\mathrm{C} 57 \mathrm{BL} / 6(\mathrm{H}-2 \mathrm{~b})$ and BALB/c (H-2d) mice, as described previously. ${ }^{19-21}$ Tracheas from donor mice were transplanted s.c. into the backs of recipient mice. Grafts are not primarily vascularized, but blood supply occurs via neovascularization by the recipient's blood vessels. The role of PD-L1 in donor versus recipient was investigated using $\mathrm{PD}-\mathrm{L}^{-1-}$ mice on the B6 background as donors or recipients, and WT BALB/c mice as the respective counterparts. In some transplant series, mice were additionally treated with a blocking monoclonal antibody against PD-1 (clone J43; BioXcell, West Lebanon, $\mathrm{NH} ; 500 \mu \mathrm{g}$ on day $0 ; 250 \mu \mathrm{g}$ on day $2,4,6,8,10$, and 12 after transplantation) or appropriate isotype control, respectively. Moreover PD- $1^{-/-}$mice (B6 background) were used as recipients. Isogeneic transplants were performed analogously, using WT and PD-L1 ${ }^{-1-}$ mice on the same background as donors and recipients. Mice were sacrificed 2, 7, or 14 days after transplantation, and grafts and spleens were harvested for further analysis. 


\section{Histology}

Tracheas were fixed in formalin-free zinc fixative (BD Biosciences, San Jose, CA), cut in half, and paraffin embedded. Cross sections of tracheal tissues ( $5 \mu \mathrm{m}$ thick) were stained with hematoxylin and eosin. Sections were graded by two independent investigators (K.S.-N. and M.Su.) who were blinded for the groups. The samples were scored using the following criteria: A luminal obliteration was scored as follows: 0 indicates no change; $1, \leq 25 \%$ obliteration; $2,25 \%$ to $50 \%$ obliteration; $3,51 \%$ to $75 \%$ obliteration; and $4, \geq 75 \%$ obliteration. Airway lining epithelial loss was scored as follows: 0 indicates no change; $1, \leq 25 \%$ circumference loss; 2 , $25 \%$ to $50 \%$ circumference loss; $3,51 \%$ to $75 \%$ circumference loss; and $4, \geq 75 \%$ circumference loss.

Immunohistochemistry staining for PD-L1 in naïve and allogeneic trachea transplantation was performed as described by Guleria et al. ${ }^{22}$ Briefly, tracheas were embedded in Tissue Tek OCT compound (Sakura Finetek, Alphen aan den Rijn, the Netherlands) and frozen in liquid nitrogen. Immunohistochemistry was performed on frozen tissue sections $(5 \mu \mathrm{m}$ thick) with PD-L1 antibody (MIH6) using the avidin-biotin technique (Vector Laboratories, Burlingame, CA).

Immunohistochemistry staining for polymorphonuclear neutrophils and macrophages was performed on paraffin sections. Briefly, sections were deparaffinized with xylene and rehydrated through graded alcohols to water. Polymorphonuclear neutrophils were stained with a rat antimouse antibody to granulocyte marker Ly-6C/6G (Gr-1; BD Biosciences). Macrophages were stained with rat anti-mouse Mac-3 (M3/84; BD Biosciences). CD4 and CD8 staining was performed on frozen sections using antibodies to mouse CD4 and CD8 (CD4: GK1.5; CD8: 53-6.7; Abcam, Cambridge, MA). A standard $\mathrm{ABC}$ vector kit (Vector Laboratories, Burlingame, $\mathrm{CA}$ ) and a diaminobenzidine reagent were used. Specificity of the staining was confirmed by using isotype control antibody. Polymorphonuclear neutrophils and macrophages were counted manually in the entire section (outside and inside of the tracheal lumen) of the allograft. CD4- and CD8-positive cells were counted in five random high-power fields under a microscope. Immunofluorescence studies for IgG, IgM, and C4d were performed with standard techniques ${ }^{23}$ using frozen sections $(4 \mu \mathrm{m}$ thick) of trachea and fluoresceinated monoclonal antibodies to mouse IgG and IgM (eBioscience, San Diego, CA) and mouse C4d (Abcam). Coded sections were scored using an epiillumination Nikon microscope (Nikon Instruments Inc., Melville, NY) and photographed with a Spot digital camera (Diagnostic Instruments Inc., Sterling Heights, MI). Evidence was sought for deposition in vessels, epithelium, and connective tissue.

\section{Flow Cytometry}

Splenocytes from transplanted animals were stained for $\mathrm{CD}^{+}$and $\mathrm{CD}^{+}$effector $\mathrm{T}$ cells $\left(\mathrm{CD} 44^{\text {high }} \mathrm{CD}^{+} \mathrm{L}^{\text {low }}\right.$ phenotype) and regulatory $\mathrm{T}$ cells $\left(\mathrm{CD} 4{ }^{+} \mathrm{CD} 25^{+} \mathrm{FoxP} 3^{+}\right)$, using fluorochrome-labeled monoclonal antibodies against CD4 (RM4-5), CD8 (53-6.7), CD44 (IM7), CD62L (MEL-14), CD25 (PC61), and FoxP3 (FJK-16s). Intracellular FoxP3 staining was performed after overnight permeabilization, using a FixPerm Kit (eBioscience). Frequencies of effector and regulatory $\mathrm{T}$ cells are given as percentage of the total $\mathrm{CD} 4^{+}$or $\mathrm{CD} 8^{+}$population.

Flow cytometry analysis of tracheal tissue was performed. Briefly, tracheal grafts were removed from recipients and rinsed with RPMI 1640 medium plus 5\% fetal bovine serum. Three tracheas were then minced using a scalpel in a digestion medium of $3 \mathrm{~mL}$ RPMI 1640 medium containing 0.1\% collagenase type 4 (Worthington Biochemical, Lakewood, NJ), $0.1 \%$ soybean trypsin inhibitor (Sigma-Aldrich, St. Louis, MO), $50 \mathrm{U} / \mathrm{mL}$ DNase (Roche, Basel, Switzerland), $10 \%$ fetal bovine serum, $10 \mathrm{~mol} / \mathrm{L}$ HEPES (Life Technologies, Carlsbad, CA), and $1 \%$ penicillin-streptomycin (Life Technologies). The suspension was placed on an agitator at $37^{\circ} \mathrm{C}$ for 30 minutes, and the digestion mixture was passed through a $70-\mu \mathrm{m}$ nylon cell strainer (BD Biosciences) to remove undigested tissue and debris. Cell suspension was then centrifuged at $151 \times g$ for 5 minutes and the pellet suspended in staining buffer. For flow cytometry, antibodies against CD326 (EpCAM, G8.8) and CD45 (104) were used. Cells were measured on a MoFlo Flow Cytometer (Cytomation, Fort Collins, CO) equipped with Spectra Physics 277-GA01 laser, and data were analyzed using Summit software version 4.3 (MoFlow). Epithelial cells were identified as $\mathrm{CD} 45^{-} \mathrm{CD} 326^{+}$.

\section{ELISPOT Assays}

ELISPOT assays were used to assess the frequency of alloreactive interferon (IFN)- $\gamma-$, IL-4-, IL-6-, and granzyme $\mathrm{B}$-producing cells, according to manufacturer's instructions (ELISPOT Kits for IFN- $\gamma$, IL-6, and IL-4 from BD Biosciences; ELISPOT Development Module for Granzyme B from R\&D, Minneapolis, MN). Usually, $0.5 \times 10^{6}$ recipientderived splenocytes were stimulated with $0.5 \times 10^{6}$ irradiated donor-type stimulator cells for 8 hours (granzyme B) or 24 hours (IFN- $\gamma$, IL-4, IL-6) at $37^{\circ} \mathrm{C}$ and $5 \% \mathrm{CO}_{2}$. The mitogen concanavalin A was used as stimulus for positive controls. The resulting red spots were counted on a computer-assisted enzyme-linked immunospot image analyzer (Cellular Technology, Kennesaw, GA), and frequencies were usually expressed as the number of spots per $0.5 \times 10^{6}$ responder cells. In some experiments, $1 \times 10^{4}$ flow-sorted $\mathrm{CD}^{+}$and $\mathrm{CD}^{+}$effector cells $\left(\mathrm{CD} 44^{\text {high }} \mathrm{CD} 62 \mathrm{~L}^{\text {low }}\right.$ phenotype) from transplanted mice were used as responder cells instead of unselected splenocytes.

\section{T-Cell Activation Assay}

$\mathrm{CD}^{+}$and $\mathrm{CD}^{+}$splenocytes from naïve $\mathrm{WT} \mathrm{B} 6$ or PD-L1 ${ }^{-1-}$ B6 mice were separately isolated using magnetic beads (Miltenyi Biotec, Bergisch Gladbach, Germany; 
purity, $>93 \%$ ), suspended in supplemented RPMI 1640 medium $(10 \%$ newborn calf serum, $1 \%$ penicillin/streptomycin, $1 \%$ L-glutamine), and stimulated with plate-bound anti-CD3 and soluble anti-CD28 (BD Biosciences) at either a low level (both antibodies at $0.5 \mu \mathrm{g} / \mathrm{mL}$ ) or at a high level of T-cell stimulation (both antibodies at $4 \mu \mathrm{g} / \mathrm{mL}$ ). After 48 hours' incubation at standard conditions $\left(37^{\circ} \mathrm{C}, 5 \%\right.$ $\mathrm{CO}_{2}$ ), cell culture supernatants were harvested and analyzed for various cytokines, using LUMINEX technology.

\section{LUMINEX Assay}

Cell-free supernatants of T-cell cultures after unspecific or allostimulation were removed after 48 hours of incubation and analyzed by a cytokine bead-based immunoassay using a mouse cytokine multiplex detection kit (Millipore, Billerica, MA), according to the manufacturer's instructions. All samples were tested in triplicate wells.

In all in vitro assays mentioned in the previous two paragraphs, the conditions were optimized with respect to numbers of responder and stimulator cells and kinetics.

\section{Statistical Analysis}

A $t$-test was used for comparison of means between two groups, and $P<0.05$ was considered significant. Data were expressed as means \pm SEM.

\section{Results}

\section{PD-L1 Is Up-Regulated in Airway Epithelial Cells on Transplantation}

To assess the expression pattern of PD-L1 on transplantation, immunohistochemical staining for PD-L1 in airway epithelial cells was performed in naïve BALB/c tracheas and in $\mathrm{BALB} / \mathrm{c}$ tracheas 2 weeks after transplantation into B6 recipients. PD-L1 expression was low in the epithelium of naïve tracheas but was significantly up-regulated in allografts, as assessed by both immunohistochemistry (Figure 1A) and flow cytometry (Figure 1B). This suggests a functional role of PD-L1 expression in the airway of tracheal transplants.

\section{Donor PD-L1 Expression Protects Tracheal Allografts from Injury}

To determine the role of PD-L1 in the donor tissue, tracheas from WT or PD-L1 ${ }^{-1-}$ B6 mice were transplanted into WT $\mathrm{BALB} / \mathrm{c}$ mice. A histopathological examination of hematoxylin and eosin-stained trachea sections revealed significantly worse outcome when donor trachea was PD- $\mathrm{L}^{-1-}$ as compared to WT donors, as assessed by the degree of luminal obliteration and airway epithelial loss 14 days after transplantation (Figure 2, A and B). Accordingly, PD-L1 ${ }^{-1-}$ allografts showed increased infiltration with $\mathrm{CD}^{+}{ }^{+}$and $\mathrm{CD} 8^{+} \mathrm{T}$ cells (Figure $2 \mathrm{C}$ ). These data emphasize a protective function of intragraft PD-L1 expression in obliteration of the airways.

\section{PD-L1 Deficiency in the Recipient Provides Protection against Allograft Injury}

To test the role of PD-L1 in the graft recipient, tracheas from WT BALB/c donor mice were grafted into WT or PD-L1 ${ }^{-l-}$ B6 recipients. Surprisingly, PD-L1 ${ }^{-1-}$ recipients showed significantly less luminal obliteration and airway epithelium loss compared to WT recipients, which showed pronounced signs of allograft injury (Figure 3, A and B). Despite the
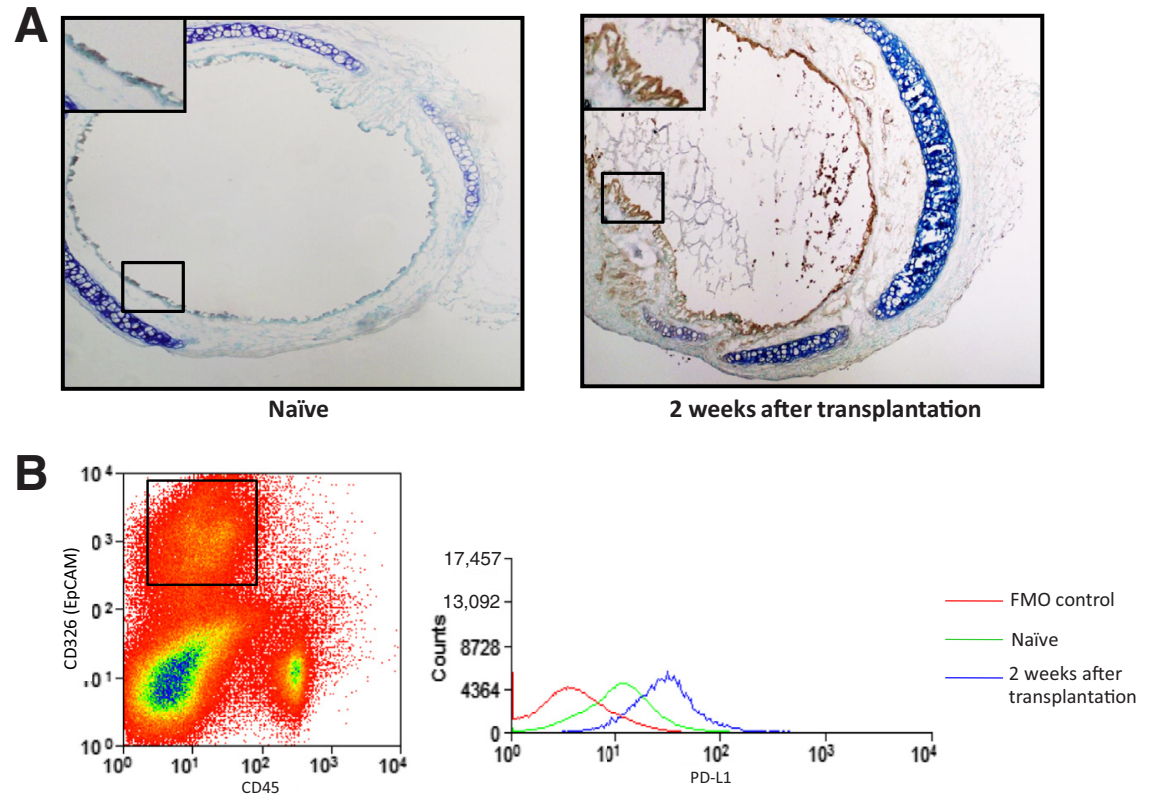

Figure $1 \quad \mathrm{PD}-\mathrm{L} 1$ is up-regulated in airway epithelial cells of tracheal allografts. A: Frozen sections of naïve tracheas and tracheal allografts at day 14 after transplantation were stained with an antibody to PD-L1 (immunohistochemistry). $\mathrm{PD}-\mathrm{L} 1$ expression is low in the epithelium of naive $B A L B / C$ tracheas but up-regulated in $B A L B / C$ tracheal allografts 14 days after transplantation into $\mathrm{B} 6$ recipients. Boxed areas indicate the tracheal epithelium and are shown at higher magnification in the insets. B: Flow cytometry was performed on tracheal tissue and $\mathrm{CD} 45^{-} \mathrm{CD} 326^{+}$cells were identified as epithelial cells. PD-L1 expression in epithelial cells was measured as fluorescence intensity. Tracheal allografts show up-regulation of PD-L1 on epithelial cells on day 14 after transplantation compared to naïve tracheas. Original magnification, $\times 10$ (A). FM0, fluorescence minus one control. 


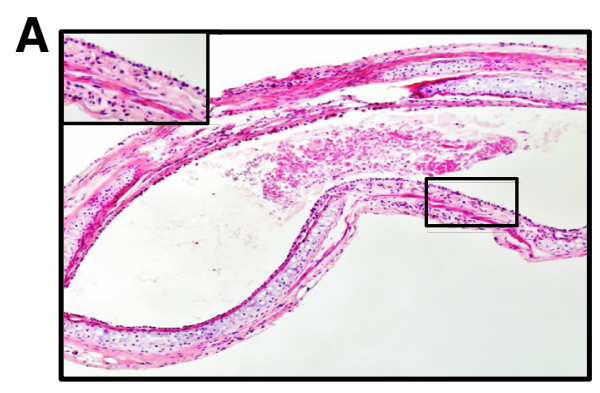

WT WT $\rightarrow$

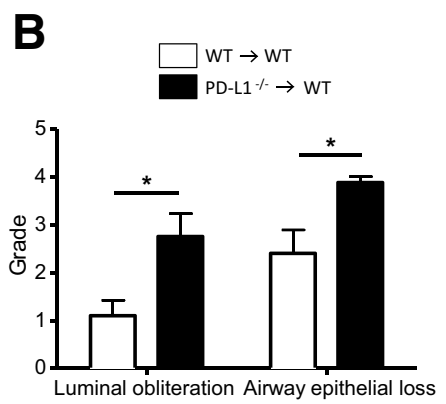

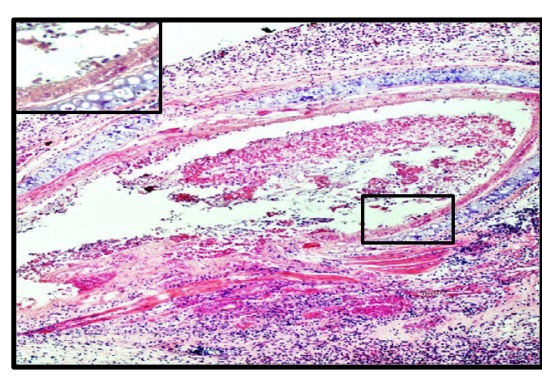

PD-L1 $\%$ WT
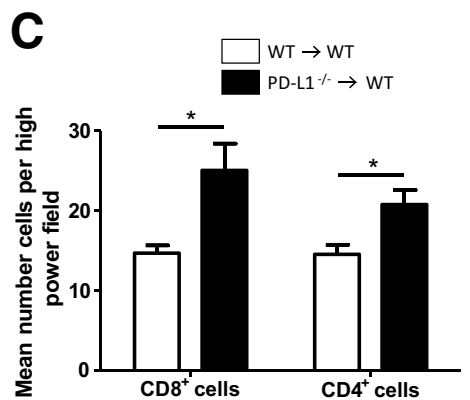

Figure 2 PD-L1-deficient donor grafts are more susceptible to B0 development. Tracheas from WT and $\mathrm{PD}-\mathrm{L}^{-/-} \mathrm{B} 6$ donors were transplanted into WT BALB/c recipients and harvested 14 days after transplantation. A: Cross sections of paraffin-embedded tracheal tissues ( $5 \mu \mathrm{m}$ thick) were stained with hematoxylin and eosin to assess the degree of luminal obliteration and epithelial loss. Boxed areas indicate the tracheal epithelium and are shown at higher magnification in the insets. B: Sections were graded by two independent investigators (K.S.-N., M.Su.) who were blinded for the groups. PD-L1 ${ }^{-/}$donor tracheas show more severe luminal obliteration and airway epithelial loss compared to WT grafts. C: Immunohistochemistry analysis of allograft infiltrating $\mathrm{CD}^{+}$and $\mathrm{CD}^{+}{ }^{\mathrm{T}}$ cells was performed on frozen tracheal sections and reveals significantly higher numbers in PD-L1 ${ }^{-/-}$allografts when compared to WT allografts. Cells were counted in five random high-power fields. Data are representative of three transplant series. $n=4$ animals per group $(\mathbf{A}-\mathbf{C}) .{ }^{*} P<0.05$. Original magnification, $\times 10$ (A).

lower degree of histopathological damage, allografts in PD-L1 $1^{-1-}$ recipients showed higher infiltration with $\mathrm{CD} 4^{+}$ and $\mathrm{CD}^{+} \mathrm{T}$ cells (Figure $3 \mathrm{C}$ ). These data reveal an unexpected role of PD-L1 in tracheal allograft recipients, given the detrimental effects of PD-L1 deficiency in tracheal allografts.

\section{PD-1 Deficiency in the Recipient Provides Protection against Allograft Injury}

As it is the action of PD-L1 on PD-1 that normally constrains the immune response, we also used $\mathrm{PD}-1^{-1-} \mathrm{B} 6$ mice as recipients of BALB/c grafts. Similar to PD-L1 ${ }^{-/-}$recipients, $\mathrm{PD}-1^{-/}$recipients were protected from luminal obliteration and airway epithelial loss (Figure 4) when compared to WT recipients. The data suggest that complete interruption of PD-1/PD-L1 signaling mediates graft-protecting effects.

T Cellular Overexpression of PD-1 Is Not a Prerequisite for Graft Protection in PD-L1-Deficient Recipients

PD-L1 ${ }^{-1-}$ recipients showed increased expression of PD-1 on $\mathrm{CD}^{+}{ }^{+}$and $\mathrm{CD}^{+}$effector $\mathrm{T}$ cells when compared to WT animals (Figure $5 \mathrm{~A}$ ). To test whether graft protection in

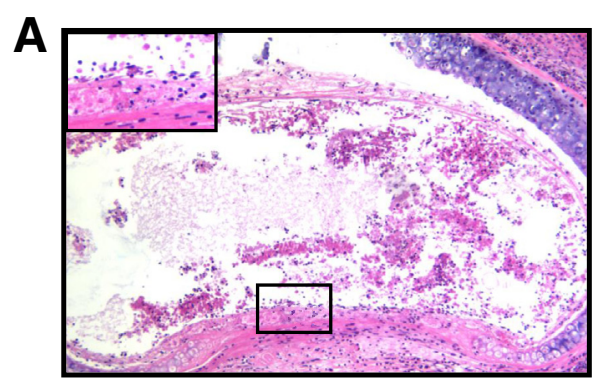

WT $\rightarrow$ WT

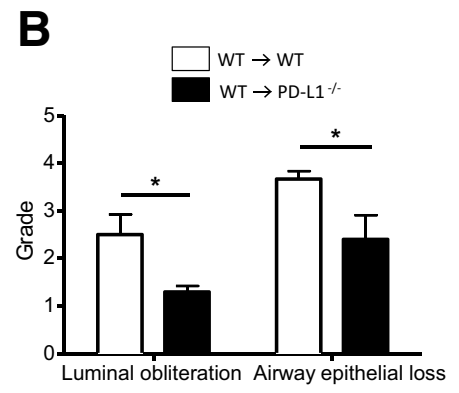

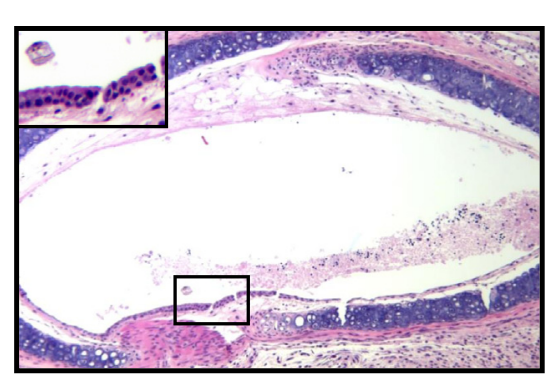

WT $\rightarrow$ PD-L1 $\%$

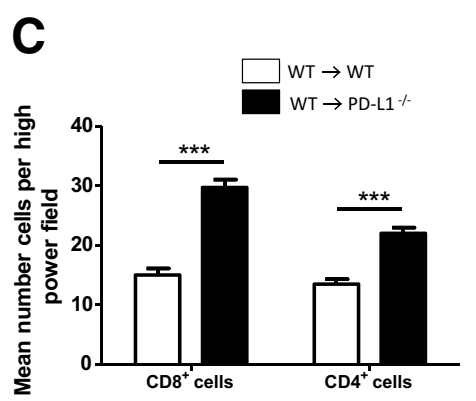

Figure 3 PD-L1-deficient recipients are protected from B0. Tracheas from WT BALB/C donors were transplanted into $\mathrm{WT}$ and $\mathrm{PD}-\mathrm{L1}^{-/-} \mathrm{B} 6$ recipients and harvested 14 days after transplantation. A: Cross sections of paraffinembedded tracheal tissues ( $5 \mu \mathrm{m}$ thick) were stained with hematoxylin and eosin to assess the degree of luminal obliteration and epithelial loss. Boxed areas indicate the tracheal epithelium and are shown at higher magnification in the insets. B: Sections were graded by two independent investigators (K.S.-N., M.Su.) who were blinded for the groups. $\mathrm{PD}-\mathrm{L}^{-/-}$recipients show significantly decreased degrees of luminal obliteration and loss of airway epithelium. C: Immunohistochemical analysis of allograft infiltrating $\mathrm{CD}_{4}^{+}$ and $\mathrm{CD} 8^{+} \mathrm{T}$ cells was performed on frozen tracheal sections and reveals significantly higher numbers in PD-L1 ${ }^{-/}$recipients, when compared to WT recipients. Cells were counted in five random high-power fields. Data are representative of four transplant series. $n=4$ animals at least per group $(\mathbf{A}-\mathbf{C}) .{ }^{\star} P<0.05,{ }^{* * *} P<0.001$. Original magnification, $\times 10(\mathbf{A})$. 
A

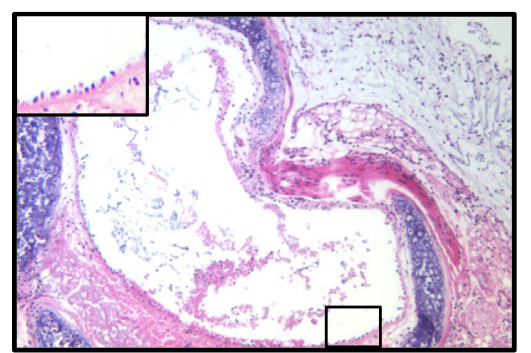

WT $\leftarrow$ WT

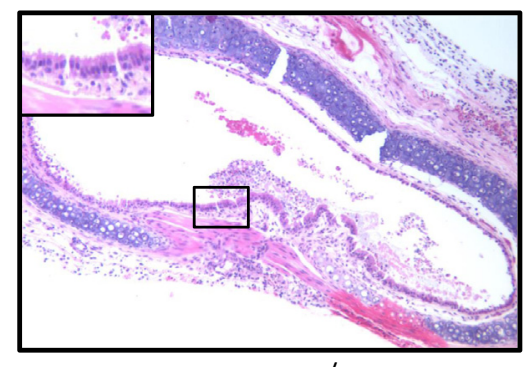

WT $\leftarrow$ PD- $1 \%$
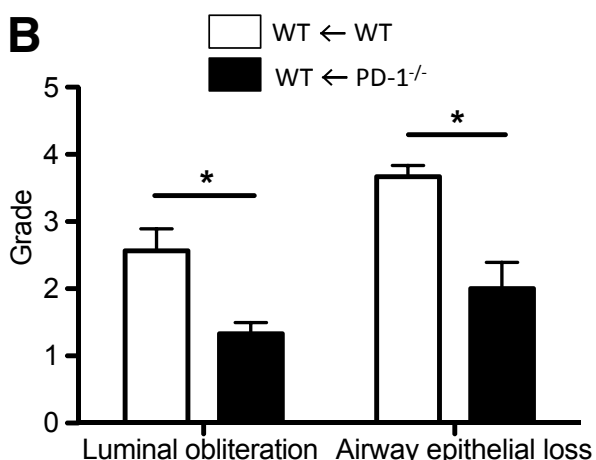

Figure 4 PD-1-deficient recipients are protected from B0. Tracheas from WT BALB/c donors were transplanted into WT and PD-1 $1^{-/-}$B6 recipients and harvested 14 days after transplantation. A: Cross sections of paraffin-embedded tracheal tissues ( $5 \mu \mathrm{m}$ thick) were stained with hematoxylin and eosin to assess the degree of luminal obliteration and epithelial loss. Boxed areas indicate the tracheal epithelium and are shown at higher magnification in the insets. B: Sections were graded by two independent investigators (K.S.-N., M.Su.) who were blinded for the groups. Histopathological grading reveals significantly reduced degrees of luminal obliteration and loss of airway epithelium in $\mathrm{PD}-1^{-1-} \mathrm{B} 6$ recipients compared to WT B6 recipients. Data are representative of four transplant series. $n=4$ animals at least per group (A and $\mathbf{B})$. ${ }^{*} P<0.05$. Original magnification, $\times 10(\mathbf{A})$.

$\mathrm{PD}-\mathrm{L}^{-/-}$recipients of WT tracheas results from increased interaction between PD-1 on recipient immune cells and PD-L1 on graft tissue, blocking anti-PD-1 monocloncal antibody was administered to $\mathrm{PD}-\mathrm{L}^{-/-}$recipients of $\mathrm{WT}$ tracheas. Interruption of the interaction between tissue PDL1 and PD-1 on recipient $\mathrm{T}$ cells did not abrogate tissue protection (Figure 5B), indicating that this interaction is not essential for the observed beneficial effects in PDL1-deficient graft recipients, and supporting the conclusion from the observation in PD-1-deficient recipients mentioned in the previous paragraph.

Given the histopathological changes, the data suggest a possible relation between PD-1/PD-L1 signaling within the recipient's immune system and the susceptibility of allografts to injury. Hypothesizing that one possible explanation for the observed results would be differences in the effector functions between WT and PD-L1/ PD-1-deficient recipients prompted us to further elucidate the systemic alloimmune responses in vitro.

\section{Tracheal Allografts Lacking PD-L1 Elicit Increased Systemic Alloimmune Responses in the Graft Recipient}

To assess the systemic alloimmune response in BALB/c WT recipients of WT B6 or PD-L1 ${ }^{-/-}$B6 grafts, we determined the percentages of splenic effector and regulatory $\mathrm{T}$ cells by flow cytometry at day 7 after transplantation. Both $\mathrm{CD}^{+}$ and $\mathrm{CD}^{+}$effector $\mathrm{T}$ cells were increased in WT recipients
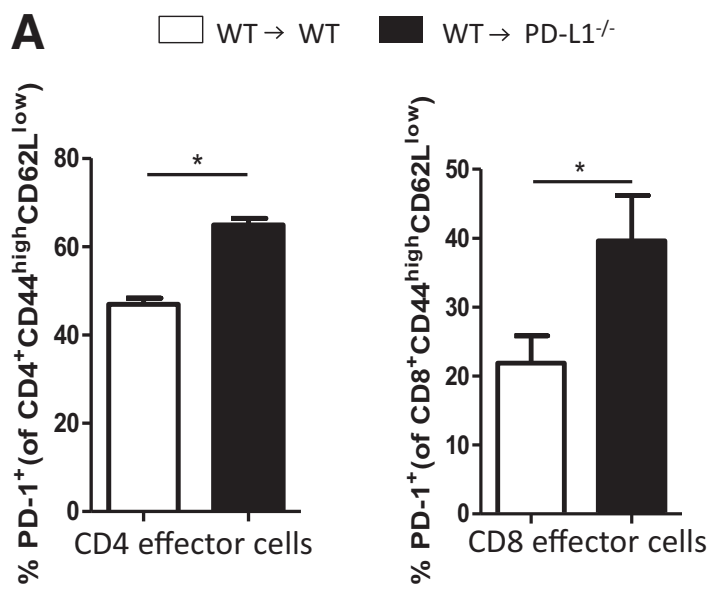

B

Figure 5 Overexpression of PD-1 on $\mathrm{CD}^{+}$and $\mathrm{CD}^{+}$effector T cells is not required for graft protection in PD-L1-deficient recipients. A: Tracheas from WT $\mathrm{BALB} / \mathrm{c}$ donors were transplanted into WT and $\mathrm{PD}-\mathrm{L1}^{-/-} \mathrm{B} 6$ recipients, and spleens were harvested 7 days after transplantation. $\mathrm{PD}-1$ expression on T-effector cells was analyzed by flow cytometry. The percentage of PD-1-positive $\mathrm{CD} 4^{+}$and $\mathrm{CD} 8^{+}$effector cells is significantly higher in PD-L1 $1^{-/-}$recipients. Data are representative of four different experiments. B: To test whether the enhanced PD-1 expression and a subsequent increased interaction between PD-1 on PD$\mathrm{L}^{-/-}$immune cells and $\mathrm{PD}-\mathrm{L} 1$ within the graft tissue mediates the protective effects observed in $\mathrm{PD}-\mathrm{L} 1^{-/-}$recipients, $\mathrm{PD}-1$ was blocked in these mice by administration of a monoclonal antibody against PD-1. Cross sections of paraffin-embedded tracheal tissues ( $5 \mu \mathrm{m}$ thick) were stained with hematoxylin and eosin to assess the degree of luminal obliteration and epithelial loss. Sections were graded by two independent investigators (K.S.-N., M.Su.) who were blinded for the groups. Histopathological scoring did not reveal any significant effects of PD-1 blockade in PD-L1 ${ }^{-/}$recipients when compared to isotype-treated controls 14 days after transplantation. Data are representative of three different experiments. $n=4$ animals per group $(\mathbf{A}$ and $\mathbf{B}) .{ }^{*} P<0.05,{ }^{* * *} P<0.001$. 
of PD-L1 ${ }^{-1-}$ tracheas, when compared to WT recipients of WT tracheas, whereas there was no difference in the frequencies of $\mathrm{T}$ regulatory cells (Figure 6A). Next, we assessed the frequencies of alloreactive, cytokine-producing splenocytes after restimulation with alloantigen, using ELISPOT assays. WT recipients of $\mathrm{PD}-\mathrm{L} 1^{-1-}$ tracheas showed increased frequencies of IFN- $\gamma-$, IL-6-, IL-4-, and granzyme B-producing splenocytes (Figure 6B). These data were confirmed by LUMINEX assays, which were performed to assess the cytokine and chemokine production of recipient $\mathrm{T}$ cells after restimulation with irradiated donortype splenocytes (data not shown). These data support a protective function of PD-L1 expression within the donor tissue.

\section{PD-L1-Deficient Graft Recipients Show Increased}

Effector T Cells but Decreased Systemic Alloreactivity after Trachea Transplantation

$\mathrm{PD}-\mathrm{L} 1^{-/-}$B6 recipients of WT BALB/c tracheas showed significantly increased percentages of splenic $\mathrm{CD}^{+}$and $\mathrm{CD}^{+}$effector $\mathrm{T}$ cells and $\mathrm{CD} 4^{+} \mathrm{T}$ regulatory cells, when compared to WT B6 recipients (Figure 7A). However, despite the increased numbers of effector $\mathrm{T}$ cells, the frequencies of IFN- $\gamma-$, IL-6-, IL-4-, and granzyme $\mathrm{B}$-producing splenocytes were significantly reduced in $\mathrm{PD}-\mathrm{L1}^{-/-}$recipients compared to WT recipients, as assessed by ELISPOT assays (Figure 7B), and these data were also confirmed by LUMINEX assays testing the cytokine production of splenocytes after restimulation with alloantigen (data not shown). In summary, these data confirm the novel dual role of PD-L1 in donor versus recipient.

\section{PD-1-Deficient Graft Recipients Show Decreased Systemic Alloreactivity after Trachea Transplantation}

Similar to $\mathrm{PD}-\mathrm{L} 1^{-/-}$recipients, $\mathrm{PD}-1^{-/-}$recipients showed decreased frequencies of cytokine-producing cells (Figure 8A), indicating a protective effect of interrupted PD-1/PD-L1 pathway within the immune system of tracheal allograft recipients per se. Blockade of PD-1 by administration of anti-PD-1 antibody in $\mathrm{PD}-\mathrm{L} 1^{-1-}$ recipients did not abrogate the observed decrease in alloreactivity (Figure 8B) (data shown for IFN- $\gamma$ only), which further underlines that the protective effect in $\mathrm{PD}-\mathrm{L} 1^{-1-}$ mice does not depend on increased PD-1 expression on PD-L1 ${ }^{-/-}$ immune cells and subsequently increased interaction with tissue PD-L1, but is because of interrupted PD-1/PD-L1 signaling among immune cells of the recipient.

\section{PD-L1-Deficient CD8 ${ }^{+}$Effector T Cells Are Hyporesponsive toward Alloantigen}

Given the discrepancy between the increased $\mathrm{T}$ effector cell numbers but decreased alloreactivity in $\mathrm{PD}-\mathrm{L} 1^{-1-} \mathrm{B} 6$ recipients, we determined the function of $\mathrm{CD}^{+}$and $\mathrm{CD} 8^{+}$
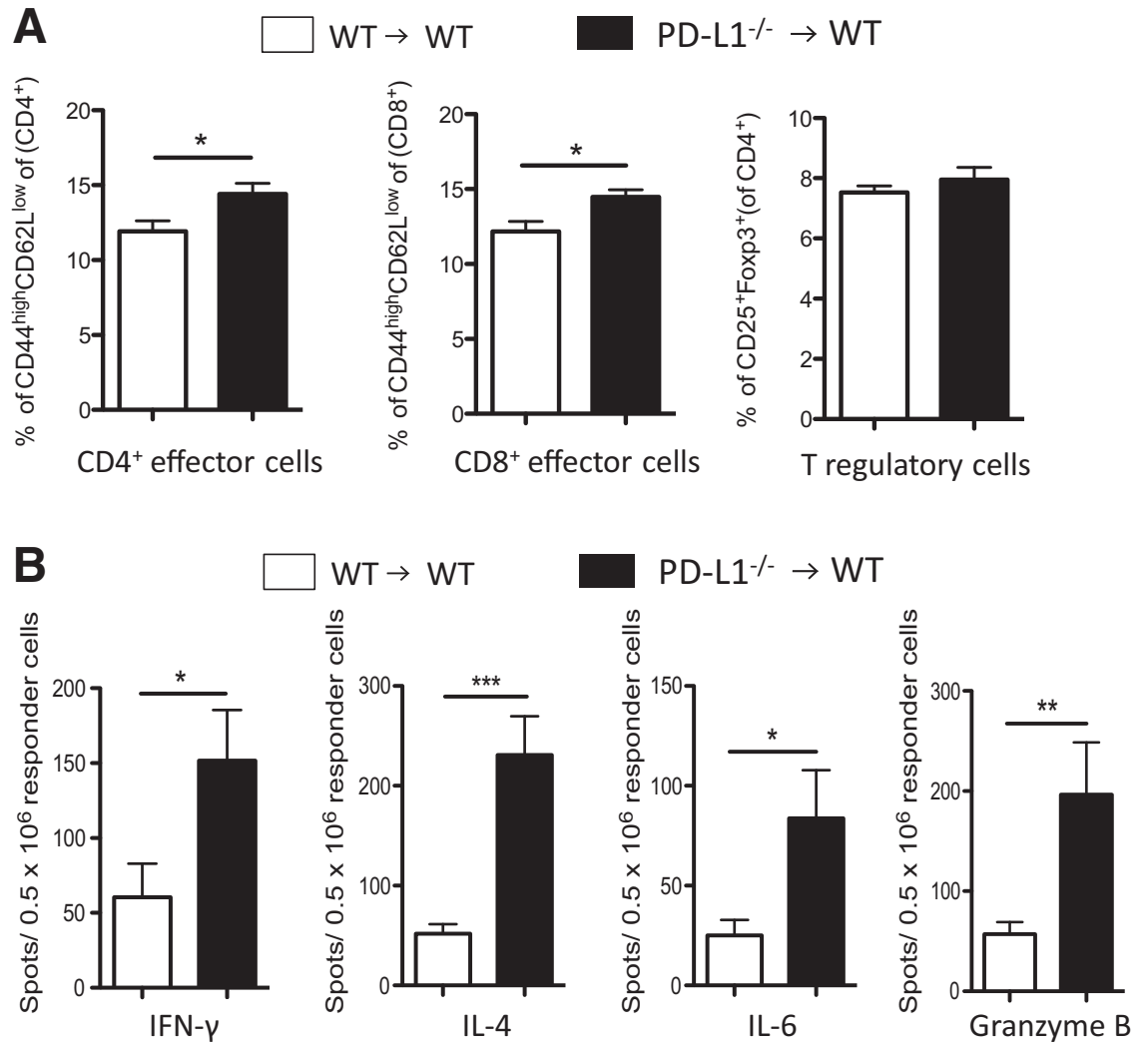

Figure 6 Recipients of PD-L1-deficient tracheal allografts show increased systemic alloimmune responses. Tracheas from WT and PD$\mathrm{L}^{-/-} \mathrm{B} 6$ donors were transplanted into WT $\mathrm{BALB} / \mathrm{c}$ recipients. To assess systemic alloimmune response in the recipient, spleens were harvested 7 days after transplantation. A: Flow cytometry analysis of $\mathrm{CD}^{+}$and $\mathrm{CD}^{+}$effector cells (CD44 ${ }^{\text {high }} \mathrm{CD} 62 \mathrm{~L}^{\text {low }}$ phenotype) of spleens from WT recipients of $\mathrm{PD}-\mathrm{L}^{-/-}$tracheas show increased percentages of $\mathrm{CD}^{+}$and $\mathrm{CD}^{+}$effector cells when compared to WT recipients of WT tracheas 7 days after transplantation. Frequencies of effector and regulatory $T$ cells are given as percentage of the total $\mathrm{CD}^{+}$or $\mathrm{CD}^{+}$population. B: Similarly, the frequencies of cytokine-producing splenocytes, as analyzed by ELISPOT assays, increase in WT recipients of $\mathrm{PD}-\mathrm{L}^{-/-}$tracheas 7 days after transplantation. Frequencies are expressed as the number of spots per $0.5 \times 10^{6}$ responder cells. ELISPOT experiments were performed in triplicate. Data are representative of three independent experiments. $n=5$ animals at least per group (A and B). ${ }^{*} P<0.05,{ }^{* *} P<0.01$, and $* * * P<0.001$ 

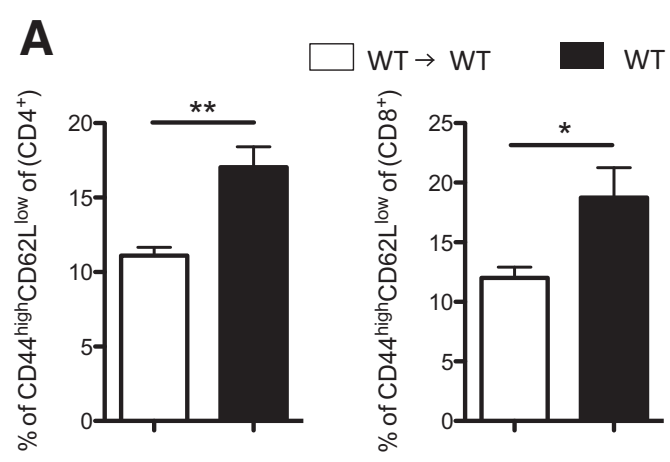

$\mathrm{WT} \rightarrow \mathrm{PD}-\mathrm{L}^{-1}$
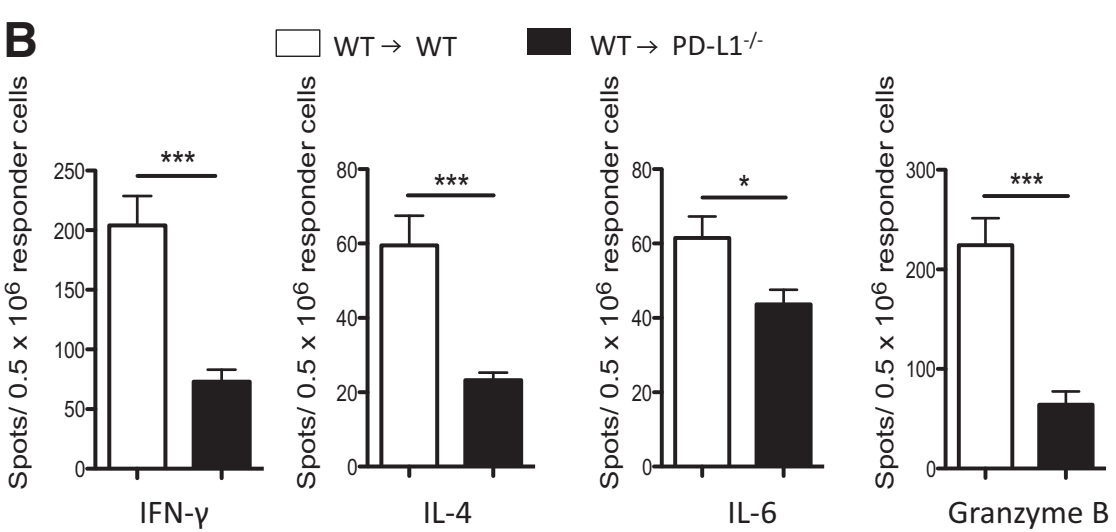

Figure 7 PD-L1-deficient recipients show decreased systemic alloimmune responses. Tracheas from WT BALB/C donors were transplanted into WT and $\mathrm{PD}-\mathrm{L1}^{-/-} \mathrm{B} 6$ recipients. To assess the systemic alloimmune response in the recipient, spleens were harvested 7 days after transplantation. A: Flow cytometry analysis of $\mathrm{CD}^{+}$and $\mathrm{CD}^{+}$effector cells (CD44 ${ }^{\text {high }}$ CD62 $\mathrm{L}^{\text {low }}$ phenotype) and $\mathrm{CD4}^{+} \quad \mathrm{T}$ regulatory cells (Tregs; $\mathrm{CD}^{+} \mathrm{CD}^{+} 5^{+} \mathrm{FoxP}^{+}$) of spleens from PD-L1 ${ }^{-/-}$recipients shows increased percentages of $\mathrm{CD}^{+}$and $\mathrm{CD}^{+}$effector cells and $\mathrm{CD}^{+}$Tregs when compared to WT recipients 7 days after transplantation. Frequencies of effector and regulatory $T$ cells are given as percentage of the total $\mathrm{CD}^{+}$or $\mathrm{CD}^{+}$population. B: Despite the increased numbers of effector $T$ cells, PD-L1 ${ }^{-/-}$recipients show decreased frequencies of cytokine-producing splenocytes 7 days after transplantation compared to WT recipients, as assessed by ELSIPOT assays. Frequencies are expressed as the number of spots per $0.5 \times 10^{6}$ responder cells. ELISPOT experiments were performed in triplicate. Data are representative of four independent experiments. $n=4$ animals per group (A and B). ${ }^{*} P<0.05,{ }^{* *} P<0.01$, and $* * * P<0.001$. effector T cells in WT and PD-L1 ${ }^{-1-}$ B6 recipients of WT $\mathrm{BALB} / \mathrm{c}$ tracheal allografts. $\mathrm{CD} 4^{+}$and $\mathrm{CD}^{+} \mathrm{T}$ effector cells (CD44 ${ }^{\text {high }}$ CD62L ${ }^{\text {low }}$ splenocytes) from transplanted mice were flow sorted and restimulated with donor-type splenocytes in an IFN- $\gamma$ ELISPOT assay. Although CD4 ${ }^{+}$ effector $\mathrm{T}$ cells from both WT and $\mathrm{PD}-\mathrm{L1}^{-1-}$ recipients generally did not show pronounced alloreactivity, WT $\mathrm{CD}^{+}{ }^{+}$effector $\mathrm{T}$ cells showed marked IFN- $\gamma$ production on restimulation with alloantigen. In contrast, $\mathrm{PD}-\mathrm{L} 1^{-/-} \mathrm{CD} 8^{+}$ effector $\mathrm{T}$ cells were hyporesponsive toward alloantigen (Figure 9A). Similar results were also obtained with PD-1-deficient effector $T$ cells (data not shown). These results possibly explain why PD-L1 ${ }^{-1-}$ recipients show a decreased alloimmune response even though $\mathrm{CD} 8^{+}$effector cells are increased in numbers. The data highlight the important role of $\mathrm{CD}^{+}$T-cell function in this model, and that blockade of PD-1/PD-L1 interaction promotes hyporesponsiveness of these cells.

\section{Function of PD-L1 in Activated T Cells Depends on Both Cell Type and Strength of Stimulation}

To test the role of PD-L1 in T cells after unspecific stimulation, $\mathrm{CD}^{+}$and $\mathrm{CD} 8^{+} \mathrm{T}$ cells from naïve $\mathrm{B} 6$ mice were isolated by magnetic cell separation and stimulated in vitro with plate-bound anti-CD3 and soluble anti-CD28, using different degrees of stimulation, as it has been suggested that the function of the PD-1/PD-L1 system depends on the level of T-cell stimulation. IFN- $\gamma$ levels were measured in the cell culture supernatants. IFN- $\gamma$ production of $\mathrm{CD} 4^{+}$ $\mathrm{T}$ cells was dependent on the strength of stimulation; however, PD-L1 ${ }^{-1-} \mathrm{CD}^{+} \mathrm{T}$ cells produced more IFN- $\gamma$ than their WT counterparts at a low degree of T-cell stimulation, and this difference was obscured at a high degree of T-cell stimulation (Figure 9B). In contrast, $\mathrm{CD} 8^{+} \mathrm{T}$ cells lacking PD-L1 generally showed decreased production of IFN- $\gamma$ when compared to PD-L1-proficient $\mathrm{CD} 8^{+} \mathrm{T}$ cells, regardless of the degree of T-cell stimulation (Figure 9C). These data show that the effect of PD-L1 expression on activated $\mathrm{T}$ cells is dependent on the respective cell type and the degree of T-cell activation.

\section{Effects of PD-L1 in Tracheal Transplantation Are Predominantly Mediated by T Cellular Alloimmune Responses}

To investigate a potential effect of PD-L1 on early graft damage (eg, by ischemia reperfusion injury), all grafts were stained for polymorphonuclear neutrophils and macrophages at day 2 after transplantation. Numbers of polymorphonuclear neutrophils and macrophages were similar between all groups (data not shown). Moreover, IgG, IgM, and C4d, indicating autoimmunity or alloantibody-mediated rejection, were not expected and not detectable in any of the grafts at days 2, 7, and 14 . In addition, WT and PD-L1 ${ }^{-1-}$ recipients of isogeneic grafts similarly showed a mild degree of tissue injury, 
A

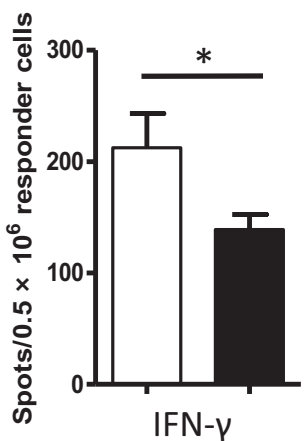

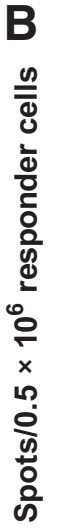

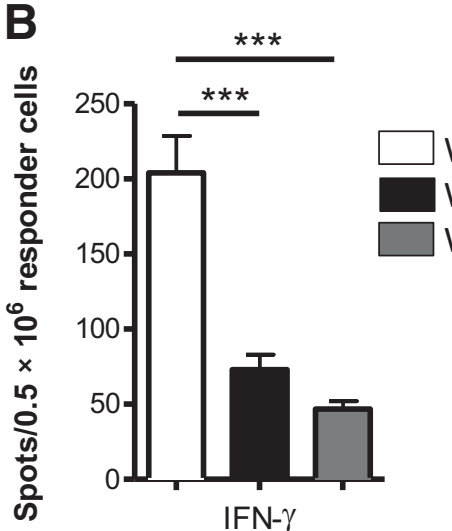

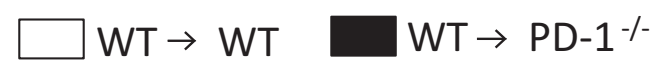
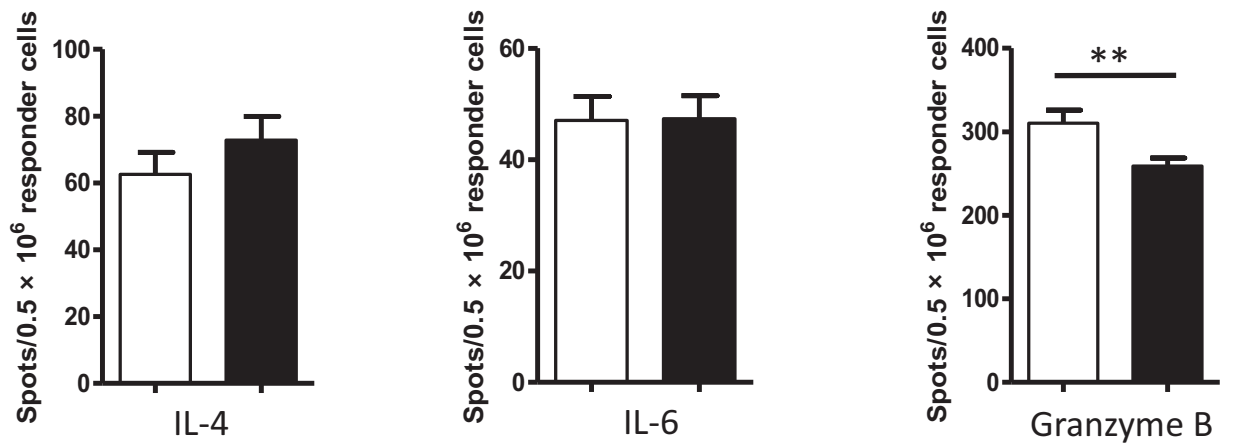

Figure 8 PD-1-deficient recipients show decreased systemic alloimmune responses. Tracheas from WT BALB/c donors were transplanted into $\mathrm{WT}$ and $\mathrm{PD}-1^{-/-} \mathrm{B} 6$ recipients or $\mathrm{PD}-\mathrm{L} 1^{-/-} \mathrm{B} 6$ recipients treated with an anti-PD-1 antibody. To assess the systemic alloimmune response in the recipient, spleens were harvested 7 days after transplantation. A: ELISPOT analysis shows significantly decreased frequencies of cytokine-producing splenocytes in $\mathrm{PD}-1^{-1-} \mathrm{B} 6$ recipients of $\mathrm{BALB} / \mathrm{c}$ tracheas 7 days after transplantation. B: $\mathrm{PD}-1$ blockade in $\mathrm{PD}-\mathrm{L}^{-/}{ }^{-}$recipients does not affect systemic alloimmune response. ELISPOT assays show similar frequencies of cytokine-producing splenocytes with and without PD-1 blockade (shown for IFN- $\gamma$ only). Frequencies are expressed as the number of spots per $0.5 \times 10^{6}$ responder cells. ELISPOT experiments were performed in triplicate. Data are representative of four different experiments. $n=4$ animals per group (A and $\mathbf{B}) .{ }^{*} P<0.05,{ }^{*} P<<0.01$, and ${ }^{* *} * P<0.001$. indicating that predominantly alloimmune reactions rather than any other causes of graft damage are responsible for the observed differences between WT and PD- $1^{-1-}$ recipients in the heterotopic tracheal transplant model.

\section{Discussion}

The costimulatory molecule PD-L1 is involved in several immunological settings, including autoimmunity, alloimmunity, and tumor immunity, and has been studied in a broad variety of experimental disease models. We tested the effects of PD-L1 on both histopathology and systemic alloimmune responses in a murine model of tracheal transplantation, as PD-L1 has not been studied in lung transplantation and obliterative airway disease.

The lung has the highest rate of rejection among all solid organ transplants, likely because of its constant exposure to atmospheric elements and pathogens, making it particularly vulnerable to immunological and inflammatory injury. ${ }^{13}$ Treatment with current immunosuppressive agents has not ameliorated obliterative airway disease, suggesting that immune injury mechanisms remain to be defined in depth.

Using a murine airway transplant model of trachea transplantation, we first showed that PD-L1 is up-regulated in the epithelium of tracheas grafted into fully major histocompatibility complex-disparate recipients compared to naive tracheas. This observation suggests a functional role of PD-L1 in the airway of tracheal transplants. We then showed that PD-L1 within the donor tissue provides allograft protection, as $\mathrm{PD}-\mathrm{L1}^{-1-}$ donor tissue showed significantly increased luminal obliteration and airway epithelial loss. This observation is in accordance with other transplant studies showing a protective role of tissue PD-L1 expression for allograft survival. ${ }^{8}$ A similar protective function of PD-L1 was also shown in another model of epithelial injury, in which $\mathrm{CD}^{+} \mathrm{T}$-cell-mediated injury to the epithelium in a renal immune injury model was abrogated when PD-L1 was expressed by the epithelium. ${ }^{24}$ Similarly, tumor cells expressing PD-L1 have been shown to escape anti-tumor immune reactions. ${ }^{25}$

More notably, we show that PD-L1 has dichotomous effects, depending on its location, as WT tracheas transplanted into PD-L1 ${ }^{-1-}$ recipients were protected from tissue injury. So far, this has not been reported in other transplant models and points to a novel function of PD-L1 in the context of a highly immunogenic model.

Although PD-L1 has been characterized as an inhibitory molecule providing $\mathrm{T}$-cell regulation on ligation to its receptor PD-1 in the vast majority of the experimental and clinical studies, this is not completely unequivocal. Several authors report that the regulatory function of PD-L1 is only 

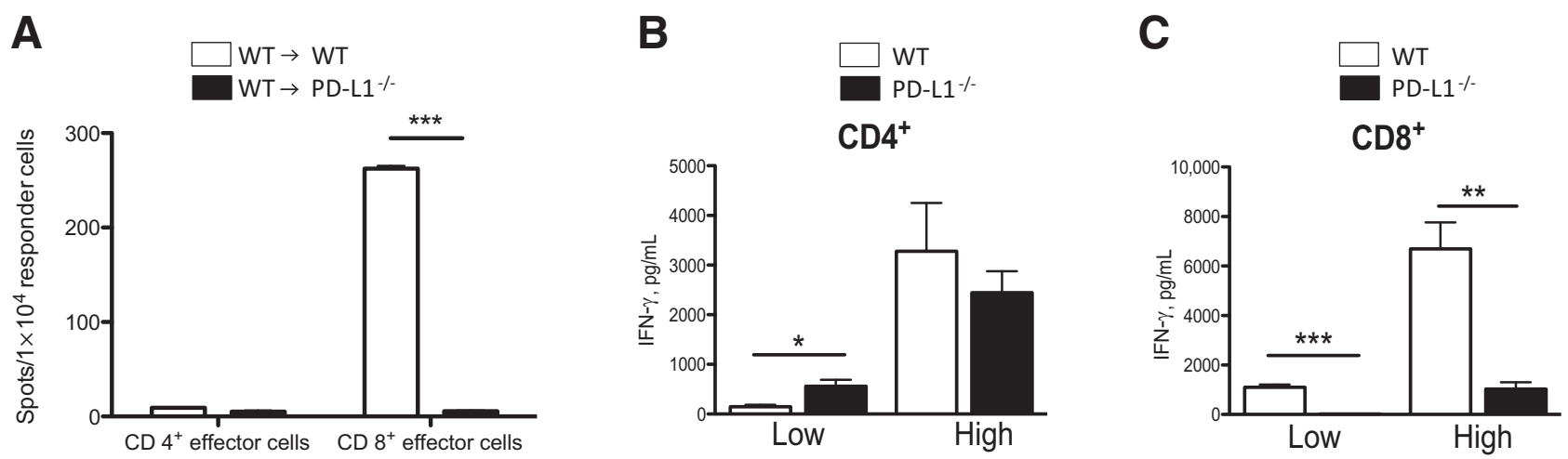

Figure 9 The function of PD-L1 depends on the cell type and the degree of T-cell stimulation. A: Tracheas from WT BALB/C donors were transplanted into WT and PD-1 $1^{-1-}$ B6 recipients. Flow-sorted $\mathrm{CD}^{+}$and $\mathrm{CD}^{+}$effector T cells (CD44 $4^{\text {high }} \mathrm{CD} 62 \mathrm{~L}^{\text {low }}$ phenotype) from WT or PD-L $1^{-1-}$ recipients at day 7 after transplantation were restimulated with donor antigen in an IFN- $\gamma$ ELISPOT assay. CD4 ${ }^{+}$T-cell response is low generally in both $\mathrm{WT}_{\text {and }} \mathrm{PD}-\mathrm{L} 1^{-1-}$ recipients, whereas $\mathrm{CD}^{+}$effector cells from WT recipients show notably increased IFN- $\gamma$ production on restimulation with alloantigen. In contrast, $\mathrm{CD}^{+}$effector T cells from $\mathrm{PD}-\mathrm{L}^{-/-}$recipients are hyporesponsive toward alloantigen. Frequencies are expressed as the number of spots per $0.5 \times 10^{6}$ responder cells. B: $\mathrm{CD} 4^{+}$ cells from naïve WT and PD-L1 ${ }^{-1-} \mathrm{B} 6$ animals were isolated by magnetic cell separation and stimulated with low and high concentrations of plate-bound antiCD3 and soluble anti-CD28. Measurements of IFN- $\gamma$ production by Luminex assays shows that the regulatory effect of PD-L1 on the activation of CD4 ${ }^{+} \mathrm{T}_{\text {cells }}$ is restricted to low levels of T-cell activation, whereas it is obscured at high levels of T-cell activation. C: $\mathrm{CD} 8^{+}$cells from naïve WT and PD-L1 ${ }^{-/-}$B6 animals were isolated by magnetic cell separation and stimulated with low and high concentrations of plate-bound anti-CD3 and soluble anti-CD28. In PD-L1 ${ }^{-/-} \mathrm{CD} 8^{+} \mathrm{T}$ cells, IFN- $\gamma$ production is generally inhibited, regardless of the degree of T-cell stimulation (Luminex). ELISPOT and Luminex experiments were performed in triplicate. Data are representative of three different experiments. $n=4$ animals per group $(\mathbf{A}-\mathbf{C}) .{ }^{*} P<0.05$, ${ }^{* *} P<0.01$, and ${ }^{* * *} P<0.001$.

present at low levels of T-cell activation, ${ }^{26,27}$ and Subudhi et $\mathrm{al}^{11}$ showed that overexpression of PD-L1 on pancreatic islet $\mathrm{B}$ cells causes accelerated rejection of transplanted allogenic PD-L1-expressing cells and increased CD8 ${ }^{+}$ T-cell proliferation.

The prevention from allograft injury in $\mathrm{PD}-1^{-/-}$ recipients points to a significant effect of the lacking interaction between PD-L1 and PD-1 per se, or to a potential yet unidentified receptor providing a positive costimulatory signal, ${ }^{28}$ within the recipient's immune system. As we and others ${ }^{29}$ observed increased PD-1 expression on effector and regulatory $\mathrm{T}$ cells from $\mathrm{PD}-\mathrm{L1}^{-1-}$ mice, we tested whether overexpression of PD-1 mediates graft protection in PD-L1 ${ }^{-1-}$ mice via interaction with tissue PD-L1. As a blocking monoclonal antibody against PD-1 did not worsen graft histology and systemic alloimmune response in PD-L1 ${ }^{-I-}$ recipients of WT tracheas, overexpression of PD-1 and subsequently increased interaction with tissue PD-L1 in these mice is not the dominant mechanism of graft protection. The histological results in PD-L1 ${ }^{-/}$recipients and even more compelling in PD- $1^{-1-}$ and anti-PD-1-treated $\mathrm{PD}-\mathrm{L}^{-1-}$ recipients suggest a connection between the PD-1/PD-L1 interaction in the recipients' immune system and susceptibility of grafts to injury. Therefore, we further analyzed the systemic immune responses in these animals.

The frequencies of cytokine-producing cells were in accordance with the respective histopathological outcome. Although WT recipients of PD-L1-deficient donor tissue exhibited an increased alloreactivity toward donor antigen, PDL1-deficient recipients, although displaying an increased number of $\mathrm{T}$ cells both in the spleen and the graft, showed a decreased alloimmune response. The observation that PD- $1^{-1-}$ and PD-L1 ${ }^{-1-}$ recipients similarly showed reduced graft pathology and systemic alloimmune responses when compared to WT recipients suggests that the interrupted PD-1/PD-L1 pathway is limiting immune responses within the recipient.

In subsequent experiments, we demonstrated that particularly $\mathrm{CD}^{+}$effector cells, which showed strong IFN- $\gamma$ production after restimulation with alloantigen in WT recipients, were hyporesponsive in PD-L1 ${ }^{-1-}$ mice, whereas IFN- $\gamma$ production by $\mathrm{CD}^{+}{ }^{+} \mathrm{T}$ cells was weak in both WT and $\mathrm{PD}-\mathrm{L1}^{-1-}$ recipients. As previously demonstrated by Freeman et $\mathrm{al}^{27}$ the regulatory effect of PD-L1 on the activation of $\mathrm{CD}^{+} \mathrm{T}$ cells during stimulation with different concentrations of anti-CD3 and anti-CD28 was restricted to low levels of T-cell activation, whereas it was obscured at high levels of T-cell activation. We were not only able to confirm these results, but also further demonstrated that PD-L1 ${ }^{-/} \mathrm{CD}^{+} \mathrm{T}$ cells generally showed decreased IFN- $\gamma$ production, regardless of the degree of T-cell activation. Taken together, our data suggest that in solid organ transplantation the net effect of the PD-1/PD-L1 pathway is not uniformly regulatory, but rather depends on both the effector cells and the degree of T-cell activation, and might be organ specific. In our experiments, $\mathrm{CD} 8^{+} \mathrm{T}$ cells proved to be highly powerful effectors, confirming the particular pathophysiological relevance of $\mathrm{CD} 8^{+} \mathrm{T}$ cells in this model, which has been shown by several authors. ${ }^{18,30,31}$

However, further investigation is needed to determine whether the changes in T-cell responses observed in this study can directly explain the apparent decrease in tracheal allograft injury, and to understand the underlying mechanisms in detail.

PD-L1 ${ }^{-1-}$ recipients showed increased percentages of $\mathrm{CD} 4{ }^{+} \mathrm{CD} 25^{+} \mathrm{FoxP}^{+}$regulatory $\mathrm{T}$ cells when compared to 
WT recipients, whereas IL-10 production by splenocytes after restimulation with allogeneic cells was low and did not differ between WT and PD-L1 ${ }^{-1-}$ recipients (data not shown). Further compensatory immunoregulative reactions might contribute to the observed phenotype, and the underlying pathophysiology remains to be fully clarified in future studies.

Other mechanisms, such as ischemia-reperfusion injury, antibody-mediated rejection, and autoimmunity, can also contribute to the development of BO syndrome, ${ }^{32}$ and it cannot be excluded that the mutant strains of mice might be less or more susceptible to such injury. However, early damage by ischemia-induced injury does not differ between both groups, as histology and infiltration of neutrophils and macrophages were similar 2 days after transplantation, and the lack of any $\operatorname{IgG}$, IgM, or C4d deposits in the graft tissues of WT and PD-L1 ${ }^{-1-}$ recipients indicates that autoimmunity and alloantibody-mediated rejection do not play a relevant role in this model.

Furthermore, the nonsterile nature of lung transplants and the resulting high immunogenicity might form the basis for the unexpected functions of PD-L1 in the trachea transplantation model. Indeed, most experimental solid organ transplant studies showing a protective effect of the PD-1/PD-L1 pathway, as recently reviewed by Riella et al, ${ }^{33}$ used transplant models with limited T-cell reactivity because of concomitant immunosuppression, additional blockade of CD28/B7 costimulation, or limited major histocompatibility complex mismatch. Although it is now generally considered that the regulatory functions of the PD-1/PD-L1 pathway might not be effective in models with strong T-cell activation, the observed adverse effects of PD-L1 in the BO model remain intriguing and highlight the biological complexity of T-cell costimulatory or coinhibitory pathways, which can have divergent functions in different tissues and under varying immunological settings. This should particularly be considered in future clinical studies targeting the PD-1/PD-L1 system by means of blocking and agonistic antibodies and fusion proteins.

\section{Acknowledgment}

We thank Dr. Robert B. Colvin (Massachusetts General Hospital) for the $\mathrm{IgG}, \mathrm{IgM}$, and $\mathrm{C} 4 \mathrm{~d}$ immunofluorescence studies and their quantification.

\section{References}

1. Li XC, Rothstein DM, Sayegh MH: PD-L1 regulates the development, maintenance, and function of induced regulatory T cells. Immunol Rev 2009, 229:271-293

2. Alegre ML, Najafian N: Costimulatory molecules as targets for the induction of transplantation tolerance. Curr Mol Med 2006, 6:843-857

3. Francisco LM, Salinas VH, Brown KE, Vanguri VK, Freeman GJ, Kuchroo VK, Sharpe AH: PD-L1 regulates the development, maintenance, and function of induced regulatory T cells. J Exp Med 2009, 206:3015-3029

4. Greenwald RJ, Freeman GJ, Sharpe AH: The B7 family revisited. Annu Rev Immunol 2005, 23:515-548

5. Chen L: Co-inhibitory molecules of the B7-CD28 family in the control of T-cell immunity. Nat Rev Immunol 2004, 4:336-347

6. Odorizzi PM, Wherry EJ: Inhibitory receptors on lymphocytes: in sights from infections. J Immunol 2012, 188:2957-2965

7. Yang J, Popoola J, Khandwala S, Vadivel N, Vanguri V, Yuan X, Dada S, Guleria I, Tian C, Ansari MJ, Shin T, Yagita H, Azuma M, Sayegh MH, Chandraker A: Critical role of donor tissue expression of programmed death ligand-1 in regulating cardiac allograft rejection and vasculopathy. Circulation 2008, 117:660-669

8. Tanaka K, Albin MJ, Yuan X, Yamaura K, Habicht A, Murayama T, Grimm M, Waaga AM, Ueno T, Padera RF, Yagita H, Azuma M, Shin T, Blazar BR, Rothstein DM, Sayegh MH, Najafian N: PDL1 is required for peripheral transplantation tolerance and protection from chronic allograft rejection. J Immunol 2007, 179:5204-5210

9. Boenisch O, Sayegh MH, Najafian N: Negative T-cell costimulatory pathways: their role in regulating alloimmune responses. Curr Opin Organ Transplant 2008, 13:373-378

10. Pilat N, Sayegh MH, Wekerle T: Costimulatory pathways in transplantation. Semin Immunol 2011, 23:293-303

11. Subudhi SK, Zhou P, Yerian LM, Chin RK, Lo JC, Anders RA, Sun Y, Chen L, Wang Y, Alegre ML, Fu YX: Local expression of B7-H1 promotes organ-specific autoimmunity and transplant rejection. J Clin Invest 2004, 113:694-700

12. Belperio JA, Lake K, Tazelaar H, Keane MP, Strieter RM, Lynch JP III: Bronchiolitis obliterans syndrome complicating lung or heart-lung transplantation. Semin Respir Crit Care Med 2003, 24 : 499-530

13. Boehler A, Estenne M: Post-transplant bronchiolitis obliterans. Eur Respir J 2003, 22:1007-1018

14. Belperio JA, Weigt SS, Fishbein MC, Lynch JP III: Chronic lung allograft rejection: mechanisms and therapy. Proc Am Thorac Soc 2009, 6:108-121

15. Shilling RA, Wilkes DS: Immunobiology of chronic lung allograft dysfunction: new insights from the bench and beyond. Am J Transplant 2009, 9:1714-1718

16. Budding K, van de Graaf EA, Otten HG: Humoral immunity and complement effector mechanisms after lung transplantation. Transpl Immunol 2014, 31:260-265

17. Xue J, Zhu X, George MP, Myerburg MM, Stoner MW, Pilewski JW, Duncan SR: A human-mouse chimeric model of obliterative bronchiolitis after lung transplantation. Am J Pathol 2011, 179:745-753

18. Richards DM, Dalheimer SL, Hertz MI, Mueller DL: Trachea allograft class I molecules directly activate and retain CD8 + T cells that cause obliterative airways disease. J Immunol 2003, 171: 6919-6928

19. Casey A, Dirks F, Liang OD, Harrach H, Schuette-Nuetgen K, Leeman K, Kim CF, Gerard C, Subramaniam M: Bone marrowderived multipotent stromal cells attenuate inflammation in obliterative airway disease in mouse tracheal allografts. Stem Cells Int 2014, 2014:468927

20. Liang OD, Kleibrink BE, Schuette-Nuetgen K, Khatwa UU, Mfarrej B, Subramaniam M: Green tea epigallo-catechin-galleate ameliorates the development of obliterative airway disease. Exp Lung Res 2011, 37: 435-444

21. Hele DJ, Yacoub MH, Belvisi MG: The heterotopic tracheal allograft as an animal model of obliterative bronchiolitis. Respir Res 2001, 2: $169-183$

22. Guleria I, Khosroshahi A, Ansari MJ, Habicht A, Azuma M, Yagita H, Noelle RJ, Coyle A, Mellor AL, Khoury SJ, Sayegh MH: A critical role for the programmed death ligand 1 in fetomaternal tolerance. J Exp Med 2005, 202:231-237

23. Miyajima M, Chase CM, Alessandrini A, Farkash EA, Della Pelle P, Benichou G, Graham JA, Madsen JC, Russell PS, Colvin RB: Early 
acceptance of renal allografts in mice is dependent on foxp3( + ) cells Am J Pathol 2011, 178:1635-1645

24. Waeckerle-Men Y, Starke A, Wuthrich RP: PD-L1 partially protects renal tubular epithelial cells from the attack of CD8+ cytotoxic T cells. Nephrol Dial Transplant 2007, 22:1527-1536

25. Zhang L, Gajewski TF, Kline J: PD-1/PD-L1 interactions inhibit antitumor immune responses in a murine acute myeloid leukemia model. Blood 2009, 114:1545-1552

26. Latchman YE, Liang SC, Wu Y, Chernova T, Sobel RA, Klemm M, Kuchroo VK, Freeman GJ, Sharpe AH: PD-L1-deficient mice show that PD-L1 on T cells, antigen-presenting cells, and host tissues negatively regulates T cells. Proc Natl Acad Sci U S A 2004, 101:10691-10696

27. Freeman GJ, Long AJ, Iwai Y, Bourque K, Chernova T, Nishimura H, Fitz LJ, Malenkovich N, Okazaki T, Byrne MC, Horton HF, Fouser L, Carter L, Ling V, Bowman MR, Carreno BM, Collins M, Wood CR, Honjo T: Engagement of the PD-1 immunoinhibitory receptor by a novel B7 family member leads to negative regulation of lymphocyte activation. J Exp Med 2000, 192:1027-1034

28. Wang S, Bajorath J, Flies DB, Dong H, Honjo T, Chen L: Molecular modeling and functional mapping of B7-H1 and B7-DC uncouple costimulatory function from PD-1 interaction. J Exp Med 2003, 197: $1083-1091$
29. Mueller SN, Vanguri VK, Ha SJ, West EE, Keir ME, Glickman JN, Sharpe AH, Ahmed R: PD-L1 has distinct functions in hematopoietic and nonhematopoietic cells in regulating $\mathrm{T}$ cell responses during chronic infection in mice. J Clin Invest 2010, 120:2508-2515

30. West EE, Lavoie TL, Orens JB, Chen ES, Ye SQ, Finkelman FD, Garcia JGN, McDyer JF: Pluripotent allospecific CD8+ effector T cells traffic to lung in murine obliterative airway disease. Am J Respir Cell Mol Biol 2006, 34:108-118

31. Shah PD, West EE, Whitlock AB, Orens JB, McDyer JF: CD154 deficiency uncouples allograft CD8+ T-cell effector function from proliferation and inhibits murine airway obliteration. Am J Transplant 2009, 9:2697-2706

32. Meyer KC, Raghu G, Verleden GM, Corris PA, Aurora P, Wilson KC, Brozek J, Glanville AR: An international ISHLT/ATS/ERS clinical practice guideline: diagnosis and management of bronchiolitis obliterans syndrome. Eur Respir J 2014, 44:1479-1503

33. Riella LV, Watanabe T, Sage PT, Yang J, Yeung M, Azzi J, Vanguri V, Chandraker A, Sharpe AH, Sayegh MH, Najafian N: Essential role of PDL1 expression on nonhematopoietic donor cells in acquired tolerance to vascularized cardiac allografts. Am J Transplant 2011, 11:832-840 